\title{
O (in)visível no cotidiano de trabalho de enfermeiros no acolhimento com classificação de risco*
}

\author{
Hosana Ferreira Rates ${ }^{1}$, \\ Ricardo Bezerra Cavalcante², \\ Marilia Alves ${ }^{3}$, \\ Regina Consolação dos Santos ${ }^{4}$, \\ Richardson Miranda Machado ${ }^{5}$, \\ Antônio Sávio de Macedo ${ }^{6}$
}

\section{RESUMO}

Estudo de caso de abordagem qualitativa que buscou compreender o cotidiano de trabalho de enfermeiros no Acolhimento com Classificação de Risco em Unidade de Pronto Atendimento. Utilizou-se o referencial teórico sobre o Cotidiano, de Michel de Certeau. Os dados foram coletados a partir de entrevistas abertas com 20 enfermeiros, observação no local de trabalho e submetidos à Análise de Conteúdo Temática. Verificamos que o cotidiano estudado possui elementos de estratégia: o protocolo de Manchester, imposições e obrigações. Tais elementos intentam isolar os sujeitos num lugar normativo, uma estrutura visível, onde podem ser controlados, vigiados e cobrados. Entretanto, o cotidiano possui táticas (in)visíveis, próprias de cada sujeito que praticam o lugar. São práticas de cuidado que burlam os elementos de estratégia. Concluímos que o cotidiano pesquisado, vai além de algo rotineiro, apesar da normatização, emergem táticas cotidianas visíveis e outras invisíveis. São práticas engenhosas, um fazer/cuidar próprio que conformam micro resistências.

Descritores: Enfermagem em Emergência; Triagem; Acolhimento; Classificação; Trabalho.

\footnotetext{
* Artigo extraído da Tese de Doutorado intitulada "O cotidiano de trabalho do enfermeiro no Acolhimento com Classificação de Risco na Unidade de Pronto Atendimento", defendida no Programa de Pós-graduação da Escola de Enfermagem da Universidade Federal de Minas Gerais, em 29 de novembro de 2016.

${ }^{1}$ Enfermeira, Doutora em Enfermagem. Professora Adjunta da Universidade Federal de São João Del Rey, Campus Centro-Oeste Dona Lindu. Divinópolis, MG, Brasil. E-mail: hosanabh@yahoo.com.br.

2 Enfermeiro, Doutor em Ciência da Informação. Professor Adjunto da Universidade Federal de Juiz de Fora, Campus Avançado Governador Valadares. Juiz de Fora, MG, Brasil. E-mail: ricardocavalcante@ufsj.edu.br.

${ }^{3}$ Enfermeira, Doutora em Enfermagem. Professor Titular da Escola de Enfermagem da Universidade Federal de Minas Gerais. Belo Horizonte, MG, Brasil. E-mail: marilix.alves@gmail.com.

${ }^{4}$ Enfermagem, Mestre em Enfermagem. Professora Auxiliar da Fundação Universidade de Itaúna. Itaúna, MG, Brasil. E-mail: reginasantos72@outlook.com.

${ }^{5}$ Enfermeiro, Doutor em Psiquiatria. Professor Associado da Universidade Federal de São João Del Rey, Campus Centro-Oeste Dona Lindu. Divinópolis, MG, Brasil. E-mail: richardson@ufsj.edu.br.

${ }^{6}$ Enfermeiro. Discente do Programa de Pós-Graduação em Enfermagem da Universidade Federal de São João Del Rey, nível Mestrado. Divinópolis, MG, Brasil. E-mail: macedo.savio11@hotmail.com.
}

Artigo recebido: 09/08/2017.

Artigo aprovado: 12/06/2018.

Artigo publicado: 05/12/2018

\section{Como citar esse artigo:}

Rates HF, Cavalcante RB, Alves M, Santos RC, Machado RM, Macedo AS. O (in)visível no cotidiano de trabalho de enfermeiros no acolhimento com classificação de risco. Rev. Eletr. Enf. [Internet]. 2018 [acesso em:

];20:v20a29. Disponível em: https://doi.org/10.5216/ree.v20.48608. 


\section{INTRODUÇÃO}

O enfermeiro, no Acolhimento com Classificação de Risco (ACCR), tem sido reconhecido como importante devido a sua formação que abrange questões técnicas, biológicas, aspectos sociais e emocionais, que tendem a viabilizar uma prática acolhedora e resolutiva ${ }^{(1)}$. A inserção do enfermeiro no ACCR tem otimizado o fluxo de pacientes, reduzido o tempo de espera pelo atendimento médico e, consequentemente, promovido a satisfação de pacientes ${ }^{(2-3)}$.

No Brasil, o ACCR tem apresentado dificuldades de implantação e desafios para institucionalização, com necessidades de readequações ${ }^{(4-5)}$; os profissionais não se sentem capacitados e apresentam sofrimentos diante das tensões vivenciadas( ${ }^{(6)}$. Ressalta-se ainda a insuficiente implementação da Política Nacional de Atenção às Urgências contribuindo para que o ACCR se torne ineficiente, principalmente no atendimento aos pacientes classificados como menos graves ${ }^{(4-5)}$.

É neste cenário complexo que o enfermeiro se vê desafiado e constrói o seu cotidiano de trabalho por meio de suas práticas, muitas vezes invisíveis, tornando necessário conhecê-lo. Certamente há um fazer desse profissional que necessita ser captado e apreendido, com vistas ao seu aprimoramento e a sua legitimação. Entretanto, é preciso apreender o cotidiano no ACCR como algo além de um simples cenário rotineiro de trabalho.

O conceito adotado, nesse trabalho sobre o cotidiano é de um espaço onde as relações de poder se manifestam e estão imbricadas em práticas cotidianas que se materializam por meio de "táticas" do fazer cotidiano que ressignificam o lugar delimitado. Representam práticas visíveis e invisíveis que (re)inventam o cotidiano, ressignificando o que lhe é dado como norma (estratégias instituídas). As estratégias intentam definir um lugar próprio que podem ser exemplificadas pelas normas, mas também por políticas, protocolos e modelos sociais de comportamento, de modo a exercer poder e conferir estabilidade espacial e temporal aos lugares que circunscrevem ${ }^{(6)}$.

Ao compreender a realidade do cotidiano de trabalho do enfermeiro no ACCR espera-se contribuir com avanços sobre o papel do profissional nesse campo de atuação, suas práticas cotidianas visíveis e invisíveis, suas táticas engendradas num saber profissional próprio. Além disso, busca-se ampliar o olhar sobre o cotidiano do enfermeiro no âmbito da urgência, e mais especificamente no ACCR.

Desta feita, a partir da perspectiva do Cotidiano de Certeau ${ }^{(7)}$ propôs-se a seguinte questão norteadora: Como se dá o cotidiano de trabalho de enfermeiros no ACCR em uma Unidade de Pronto Atendimento? Neste estudo buscou-se compreender o cotidiano de trabalho de enfermeiros no Acolhimento com Classificação de Risco em uma Unidade de Pronto Atendimento.

\section{MÉTODO}

Estudo de caso único, de abordagem qualitativa, que propõe elucidar um fenômeno ainda inédito ${ }^{(8)}$, que neste caso, trata-se da unidade de análise cotidiano de trabalho de enfermeiros no ACCR. Nesta pesquisa adotouse a perspectiva do Cotidiano de Certeau ${ }^{(7)}$, caracterizado como algo além do rotineiro, o que permite avançar no conhecimento das práticas visíveis e invisíveis de enfermeiros. Justifica-se o uso da abordagem qualitativa pela necessidade de captar o fenômeno que se constrói na vivencia dos sujeitos, suas percepções e subjetividades ${ }^{(9)}$.

O cenário de estudo foi uma Unidade de Pronto Atendimento (UPA) de um município de médio porte do sudeste brasileiro. O município é sede da Superintendência Regional de Saúde e referência para 54 municípios em 
seu entorno. A UPA é considerada de Porte III, com capacidade para atender até 350 pacientes dia ${ }^{(10)}$. A opção por realizar o estudo nessa unidade se justificou pelo acesso dos pesquisadores e por ser a única UPA do município.

Na UPA havia um total de 22 enfermeiros. Foram incluídos 20 participantes que obedeceram aos seguintes critérios de inclusão: experiência profissional mínima de dois anos, curso de especialização em urgência/emergência; realização de ACCR e assistência direta no período diurno e noturno; como critérios de exclusão: experiência profissional inferior a dois anos, não realização de especialização em urgência/emergência; e ações exclusivas na assistência.

A coleta dos dados foi realizada por meio de observação do cotidiano de trabalho e entrevistas semiestruturadas, realizadas em sala da UPA, pelos pesquisadores previamente treinados para a coleta de dados. As entrevistas foram gravadas, transcritas na íntegra e tiveram duração média de 40 minutos.

No roteiro de entrevista havia perguntas relacionadas ao perfil dos respondentes e as seguintes questões: Fale sobre o seu cotidiano no Acolhimento com Classificação de Risco; Fale sobre as práticas que realiza em seu cotidiano; Gostaria de acrescentar algo sobre o seu cotidiano de trabalho? As entrevistas foram identificadas com a letra $E$, seguida do número da entrevista de um a 20.

Optou-se, também, pela técnica da observação, tendo em vista que a coleta de dados por meio de observação é relevante para o estudo do atendimento de emergência, pois fornecem informações detalhadas sobre os eventos, situações, atividades e sistemas de conhecimento que dão forma ao ambiente de atendimento de emergência ${ }^{(11)}$. As observações foram registradas no diário de campo como Notas de Observação (NO). A coleta de dados ocorreu entre os meses de janeiro e março de 2015.

Os dados foram submetidos à Análise de Conteúdo Temática ${ }^{(12)}$. Na 1a fase realizou-se a Pré-análise ou Leitura flutuante: o primeiro contato com os documentos que consistiu em analisar e conhecer o texto; realizouse a preparação do material: as notas da observação registradas no diário de campo e as transcrições das entrevistas constituíram o corpus da pesquisa.

Na 2a fase realizou-se a exploração do material, sua codificação. Foram extraídas as unidades de registro, os núcleos de sentido, as unidades de contexto e por fim as categorias temáticas. Na 3 a fase os resultados foram tratados, emergindo duas categorias: "As Estratégias no Acolhimento com Classificação de Risco: o protocolo de Manchester, imposições e obrigações" e "As táticas no cotidiano do Acolhimento com Classificação de Risco".

A pesquisa obedeceu a Resolução 466/2012 do Conselho Nacional de Saúde e foi aprovada pelo Comitê de Ética em Pesquisa com Seres Humanos da Universidade Federal de Minas Gerais sob parecer no 799.271/2014. Os participantes manifestaram anuência com a pesquisa mediante assinatura do Termo de Consentimento Livre e Esclarecido (TCLE).

\section{RESULTADOS}

\section{As Estratégias no Acolhimento com Classificação de Risco: o protocolo de Manchester, imposições e obrigações}

O Protocolo de Manchester utilizado na classificação de risco destaca-se como norteador do ACCR, que poderia potencializar decisões assertivas e diminuir possibilidades de erros. Além disso, nas observações e entrevistas foi possível verificar que o Protocolo esconde incertezas cotidianas, gerando a falsa sensação de 
segurança, onde aquilo que não se enquadra na norma (protocolo) pode ser excluído, pois tem o respaldo do mesmo.

[...] Os enfermeiros fazem a classificação a partir do protocolo. Parecem se sentir seguros com ele. Alguns chegam a dizer que são o seu respaldo técnico (NO).

O risco de você errar numa triagem de falar assim: esse aqui é verde e ele pode esperar tanto tempo [...] O risco diminuiu bastante porque você está norteado! (E5).

O Protocolo, como uma estratégia, estaria valorizando um saber legitimado definido a priori e inibindo a classificação baseada no conhecimento próprio dos sujeitos e suas concepções.

Antes de implantar o Protocolo de Manchester, a gente tinha certa classificação de risco no antigo Pronto-Socorro. Só que era assim... não tinha nenhum protocolo, você ia mais pelo seu conhecimento de forma empírica (E17).

O protocolo serve como um conhecimento validado e direcionador (NO).

Outra característica do Protocolo que Ihe confere status de estratégia é o seu efeito de padronização sobre a linguagem dos sujeitos envolvidos (profissionais e usuários).

[...] Às vezes a gente perde um paciente "caladinho" que não fala da dor, aí quando vê é um paciente grave, infartado, que está ali "quietinho" sentado. Sem a classificação você não tinha parâmetro para medir isso. Normalmente a tendência é dar mais atenção para o paciente que grita: "Ai! Ai! Ai!" Esse paciente todo mundo apoia e aquele que está quietinho a gente acha que está bem. (E14).

As imposições e obrigatoriedades foram outras formas de materialização das estratégias no ACCR que emergiram nos relatos.

[...] o nosso coordenador falou assim: 'todos vão ter que passar em todos os setores [inclusive classificação], não tem jeito agora, ou quem não quiser vai ter que sair do pronto-socorro' [...] mas eu não gosto muito da classificação, eu acho que tinha que ser uma aptidão, porque eu especializei, fiz pós-graduação em UTI, residência em cardiologia, eu queria trabalhar na minha área, mas como eu trabalho em uma UPA não posso escolher (E1).

\section{As táticas no cotidiano do Acolhimento com Classificação de Risco}

Há o reconhecimento do protocolo de Manchester como estratégia que norteia o fazer no ACCR, contudo, a passividade em aceitá-lo como uma norma não se concretiza como esperado, sendo constantemente transgredido. Esta é uma primeira tática, a de "burlar" a classificação devido às situações circunstanciais (demora do médico em atender e tempo de espera do paciente).

[...] acaba que o enfermeiro muitas vezes começa a burlar a classificação. Ele burla a classificação porque o médico demora a atender, porque o paciente está reclamando ou porque está cheio demais. Assim, gente perde o respaldo e o objetivo do protocolo. [...] a tendência é você voltar a classificar como eram antigamente sem o protocolo (E12)!

A postura passiva em aceitar o protocolo como o fazer legitimado continua a ser desconstruído por meio de críticas tecidas do que é normatizado (fluxogramas, software Triagem em Unidade de Saúde - TRIUS, tempo previsto) e a comparação com as demandas da realidade que se estabelece no ACCR.

Tem coisas no TRIUS que não encaixam. Por exemplo, às vezes a gente avalia um paciente, mas a gente não consegue encaixar ele no programa. (E8).

[...] o tempo nosso seria de três minutos para cada paciente, o que às vezes não dá porque o TRIUS realmente é muito lento, é um problema nosso (E16).

Outra tática sutil reconhecida pelos enfermeiros é o acordo entre profissionais para priorizar o atendimento daqueles usuários que possuem a mesma classificação, a partir de seus julgamentos e afinidades, definindo quem deverá ser atendido com prioridade. 
Eu tenho uma interação muito boa com os funcionários da recepção e com o médico que está atendendo. Então eles já começam a "priorizar" o paciente porque às vezes chega um para fazer a ficha e observou que ele precisa ser triado na frente de outros que estão esperando. É uma ajuda muito grande, ele me adianta essa ficha e eu também tendo confiança com o profissional médico consigo também levar isso direto e passar até na frente de outros da mesma cor que estão esperando (E7).

Os usuários também têm suas táticas, resistem à classificação de risco e não aceitam a norma tal como acontece.

[...] percebo que a população não aceita bem a classificação, ficam a todo tempo questionando a cor recebida, entendem sempre que o seu problema é prioritário, ficam inquietos... (NO).

O ACCR é meio estressante, não por causa do sistema de classificação, mas por causa da população porque parte dela ainda não compreendeu o processo de triagem, a Manchester (E7).

A postura ativa do usuário em resistir ao normatizado no ACCR, assume uma exacerbação manifestada em agressões que acabam por gerar sofrimento nos profissionais.

A gente ali na frente fala que é porta de entrada. Assim tudo acontece ali na frente! Já houve casos de ser agredido verbalmente, dependendo se a gente não mantiver distância eles batem na gente! (E20).

[...]. Eu já estive quase desistindo por causa dessa parte de agressão física, verbal, porque gera um desconforto muito grande. Nós tivemos colegas assim, eu também passei por isso, de precisar tomar medicação para tolerar o trabalho e tudo mais. Hoje estou mais tranquila em relação a isso, mas já fiz um combinado com o chefe. Eu tenho um tempo limitado para ficar aqui, não pode me deixar muito tempo aqui porque eu começo a "surtar" (E7).

Neste cenário, o enfermeiro assume, no imaginário do usuário a representação de uma dominação que pode garantir ou negar a possibilidade de cuidado no ACCR. Assim, por estar na linha de frente (classificação) é culpabilizado, assume a representação da norma, é o “outro" como o lugar do problema ao olhar do usuário.

Eles oprimem muito a gente! No sentido assim de:

Ah a gente está ali, estou aqui há três horas esperando, me pôs uma pulseira verde, você é culpado. Eles veem a gente como um vilão aqui (E15).

Como um dos pacientes estava muito agressivo, pois queria ser atendido rapidamente, a enfermeira logo tratou de classificálo na cor amarela. O próprio paciente disse que não aceitaria verde ou azul (NO).

O médico também é apontado como aquele que exerce certo "boicote" à classificação de risco. Sua tática também está em resistir, desconhecer e criticar.

[...] Um dos médicos abordou a enfermeira e questionou "Porque que você pôs isso?" Ele criticou a classificação e disse que era para chamar o paciente sem classificar. Continuou falando que estavam fazendo as coisas ali do jeito que queriam (NO).

\section{DISCUSSÃO}

O cotidiano no ACCR é circunscrito por elementos que o definem: uma política nacional; um protocolo assistencial; imposições e punições. Tais elementos podem ser compreendidos como estratégias de delimitação de um lugar próprio no qual há um fazer delimitado que se espera ser cumprido(7).

A linguagem escrita é um instrumento de poder que tende a organizar os dados da produção socioeconômica e consagra uma divisão social, privilegiando aquele que domina os códigos da escrita ${ }^{(7)}$. Neste sentido, as estratégias no cotidiano do ACCR, principalmente por meio do protocolo de Manchester, buscam isolar o sujeito num lugar circunscrito, de domínio técnico, prescritivo e validado.

Os protocolos de cuidado à saúde surgem como instrumentos que visam orientar a gestão do cuidado. Esta é uma tentativa de validar e legitimar o cuidado sustentado na associação entre a prática e a evidência científica, mas que não comporta novas maneiras de fazer que também são praticadas no cotidiano do enfermeiro(13) 
Apesar dos enfermeiros deste estudo, em um primeiro momento, deixarem transparecer passividade em aceitar um protocolo, um saber prescrito, há a ressignificação do sistema proposto em seu cotidiano no ACCR. O ato de "burlar a classificação" e não cumprir os tempos pré-determinados são elementos que caracterizam um fazer diferente do preconizado.

Além disso, "negociações" relacionadas à definição da ordem de priorização do atendimento de usuários são acordos não materializados em normas visíveis. Percebe-se que, por um lado, no contexto do trabalho em enfermagem existe uma lógica dada pela razão instrumentalizadora que vai além do prescrito. Por outro, um cotidiano que abriga as táticas (o fazer real) que criam seus movimentos e suas invenções, que são ações diferenciadas de cada profissional que reinventam o cotidiano para escapar dos modelos dominantes ${ }^{(7-14-15)}$.

A resistência e o burlar do protocolo atendem questões para apaziguamento de conflitos entre a enfermagem, a população e a equipe médica, que se conformam como situações circunstanciais ${ }^{(7)}$. As invenções conformam-se como diferentes maneiras de fazer, acordos e negociações utilizados para atender o que emerge no cotidiano. Assim, esses processos são ancorados nas táticas de cada indivíduo ao construir suas interações, modificando processos, criando novos percursos e rompendo com a lógica formal das estratégias que circunscrevem o $\mathrm{ACCR}^{(7)}$.

Além dos profissionais, os usuários também teceram táticas que constituíram o cotidiano no ACCR. A realidade pode refletir a utilização de serviços de emergência pela população de maneira equivocada ao procurar a unidade não em casos de emergências, mas como única porta de acesso ao serviço de saúde ${ }^{(14)}$.

Outra postura do usuário é responsabilizar o enfermeiro pela ausência ou ineficiência de assistência, por seu suposto não reconhecimento do direito do outro em ser atendido primeiro, culpá-lo, lançar sobre ele o rótulo de "vilão". Nas palavras de Certeau(7) "É sempre o outro, sem responsabilidades próprias (a culpa não é minha, mas do outro: o destino) e de propriedades particulares que limitam o lugar próprio". Então, para o usuário, resistir, rotular, culpar, deslocando a responsabilidade pelo problema para outro, pode ser uma oportunidade de moldar a norma, pressionar a passagem por suas brechas, potencializando garantias em suas demandas por cuidado. Aqui está uma ação invisível, construída na intencionalidade do usuário ativo em suas escolhas. Entretanto, na perspectiva de Certeau ${ }^{(7)}$, estes atos dos usuários revelam o cotidiano como um campo de batalhas complexo onde as ações são voltadas ao atendimento das demandas, nem sempre racional.

O campo de batalhas é repleto de práticas ressignificadas que levam a certa liberdade e micro resistências (in)visíveis que, por sua vez, fundam micro liberdades, mobilizando recursos (in)suspeitos e, assim, deslocam as fronteiras verdadeiras da dominação dos poderes ${ }^{(7)}$. Neste campo, cada um com seu jogo de micro resistências/micro liberdades torna o ambiente de trabalho tenso, conflituoso, estressante, submetendo usuários e profissionais ao risco de sofrimento(16-17).

Também se verificou tensões entre médicos e enfermeiros no cotidiano do ACCR que se estabelecem a partir do Protocolo de Manchester, promovendo certa visibilidade do enfermeiro, colocando-o como um elemento interposto entre o médico e o usuário. Entretanto, não se pode entender a visibilidade conferida ao enfermeiro como a representação de sua autonomia no ACCR. Isto é claro, na compreensão formal que se tem de autonomia como a "capacidade de governar-se pelos próprios meios" onde a autonomia está além do prescrito, relacionado com o fazer com habilidade e competência ${ }^{(18)}$. Pensar os indivíduos como sujeitos autônomos é 
considerá-los como protagonistas nos coletivos dos quais participam, corresponsáveis pela produção de si e do mundo em que vivem.

A autonomia do enfermeiro, na sua formalidade conceitual, não se materializou no cotidiano do ACCR. A visibilidade e o destaque conferidos ao enfermeiro o enquadram no lugar próprio conforme Certeau, pois o acolhimento é geralmente realizado por este profissional.

As maneiras como as táticas se desenvolvem no cotidiano estudado reforçam a autonomia do médico, uma vez que ele continua a definir a ordem dos acontecimentos relacionados à assistência aos usuários, inclusive como a classificação deverá acontecer. Neste contexto, o enfermeiro de forma astuciosa imprime novas maneira de fazer no cotidiano, tais como burlar a classificação, fazer de forma diferente do que está preconizado, responder às pressões dos usuários por meio da classificação de forma assistemática, buscar esquivar do olhar vigilante do médico, do usuário e das pressões políticas do sistema.

No contexto de trabalho do enfermeiro existe diferença entre o trabalho praticado, e o que é prescrito por protocolos e normatizações, bem diferente do trabalho real, (re)inventado na invisibilidade do profissional no seu contexto de atuação. O cuidado praticado nem sempre é o que foi prescrito e normatizado; o cuidar vai além dos protocolos, que empodera e confere autonomia ao profissional, mesmo na invisibilidade de suas ações no cotidiano do enfermeiro ${ }^{(15)}$. Esse cenário é determinado por variadas singularidades do sujeito que necessita do cuidado, onde o enfermeiro cria suas liberdades de fazer e imprime saber ao cuidado prestado ao individuo, onde sua autonomia é o seu exercício da invisibilidade ${ }^{(15)}$.

\section{CONCLUSÃO}

O cotidiano dos enfermeiros no ACCR é delimitado por estratégias visíveis que normatizam e padronizam o seu fazer. Por outro lado, também abarca táticas como práticas engenhosas e repletas de intencionalidades, (re)inventando o sistema cultural previamente estabelecido; os usuários resistem à classificação, os profissionais tecem acordos, burlam a norma, desenvolvem práticas (in)visíveis, estabelecendo uma rede de micro resistências.

O enfermeiro cumpre as normas e articula novos modos de cuidado a partir de situações que o pressionam a (re)inventar o cuidado para responder as demandas cotidianas da população e do serviço, que nem sempre são convergentes. Trata-se de um cotidiano de trabalho tecido a partir do uso de estratégias e da criação astuciosa de táticas como possibilidade de dar resposta às demandas de usuários e profissionais. O enfermeiro realiza um trabalho relevante e aparentemente visível, mas sua invisibilidade aflora quando este trabalho é determinado por demandas da população e de médicos nos processos que envolvem o ACCR. Esta investigação contribuiu para clarificar a prática cotidiana de enfermeiros no ACCR, porém o estudo possui a limitação de ter sido realizado em apenas um serviço de uma cidade do interior do estado de Minas Gerais. São necessários outros estudos, que avancem na compreensão do complexo cotidiano de trabalho de enfermeiros em unidades de urgência e no ACCR, que abriga estratégias e táticas (o fazer real) na construção e reconstrução de seus saberes e práticas.

\section{Financiamento}

O estudo contou com o apoio financeiro da Coordenação de Aperfeiçoamento de Pessoal de Nível Superior (CAPES) e do Conselho Nacional de Desenvolvimento Científico e Tecnológico (CNPq). 


\section{REFERÊNCIAS}

1. Silva PL, Paiva L, Faria VB, OhI RIB, Chavaglia SRR. Triage in an adult emergency service: patient satisfaction. Rev Esc Enferm USP [Internet]. 2016 [acesso em: 04 dez. 2018];50(3):427-33. Disponível em: https://doi.org/10.1590/S0080-623420160000400008. 2. Costa MAR, Versa GLGS, Bellucci Júnior JÁ, Inoue KC, Sales CA, Matsuda LM. Acolhimento com Classificação de Risco: Avaliação de Serviços Hospitalares de Emergência. Esc. Anna Nery [Internet]. 2015 [acesso em: 04 dez. 2018];19(3):491-7. Disponível em: http://www.scielo.br/scielo.php?script=sci_arttext\&pid=S1414-81452015000300491\&lng=pt\&nrm=iso\&tlng=pt.

3. Antonelli RC, Bellucci Junior JA. Gerenciamento de enfermagem em serviço hospitalar de emergência: revisão integrativa da literatura. Semina: Ciências Biológicas e da Saúde [Internet]. 2014 [acesso em: 04 dez. 2018]35(2):137-46. Disponível em: https://doi.org/10.5433/1679-0367.2014v35n2p137.

4. sss. Welcoming with risk classification in teaching hospitals: assessment of structure, process and result. Rev Lat Am Enfermagem [Internet]. 2013 [acesso em: 04 dez. 2018];21(5):1179-87. Disponível em: https://doi.org/10.1590/\$0104-11692013000500023. 5. Versa GLGS, Vituri DW, Buriola AA, Oliveira CA, Matsuda LM. Assessment of user embracement with risk rating in emergency hospital services. Rev Gaucha Enferm [Internet]. 2014 [acesso em: 04 dez. 2018];35(3):21-28. Disponível em: https://doi.org/10.1590/1983-1447.2014.03.45475.

6. Sakai AM, Rossaneis MA, Haddad MCFL, Sardinha DSS. Sentimentos de enfermeiros no acolhimento e na avaliação da classificação de risco em pronto-socorro. Rev Rene [Internet]. 2016 [acesso em: 04 dez. 2018];17(2) 233-41. Disponível em: http://periodicos.ufc.br/rene/article/view/3007.

7. Certeau MA. Invenção do cotidiano: artes de fazer. 15a ed. Petrópolis: Vozes; 2014.

8. Yin RK. Estudo de caso: planejamento e métodos. 4ạ ed. Porto Alegre: Bookman; 2015.

9. Minayo MCS. Amostragem e saturação em pesquisa qualitativa: consensos e controvérsias. Revista Pesquisa Qualitativa [Internet]. 2017 [acesso em: 04 dez. 2018];5(7):1-12. Disponível em: https://editora.sepq.org.br/index.php/rpq/article/view/82. 10. Prefeitura Municipal de Divinópolis, Secretaria Municipal de Administração, Orçamento e Finanças. PPA - Plano Plurianual 2014 - 2017. Revisão 2016 [Internet]. Divinópolis: Prefeitura Municipal de Divinópolis; 2015 [acesso em: 04 dez. 2018]. Disponível em: http://www.divinopolis.mg.gov.br/publicos/03_ppa16.pdf.

11. Fry M, Curtis K, Considine J, Shaban RZ. Using observation to collect data in emergency research. Australas Emerg Nurs J [Internet]. 2017 [acesso em: 04 dez. 2018];20(1):25-30. Disponível em: https://doi.org/10.1016/i.aenj.2017.01.001.

12. Bardin L. Análise de conteúdo. Lisboa: Edições 70; 2015.

13. Alves KYA, Salvador PTCO, Tourinho FSV, Santos VEP. Análise do conceito "protocolos de enfermagem" a partir da visão evolucionária de rodgers. Revista de Enfermagem UFPE On Line [Internet] 2014 [acesso em: 04 dez. 2018];8(1):177-82. Disponível em: https://periodicos.ufpe.br/revistas/revistaenfermagem/article/view/9622.

14. Marconato RS, Monteiro MI. Risk classification priorities in an emergency unit and outcomes of the service provided. Rev Lat Am Enfermagem [Internet]. 2017 [acesso em: 04 dez. 2018];25: e2974. Disponível em : https://doi.org/10.1590/15188345.2345.2974.

15.Fonseca MLG, Sá MC. A insustentável leveza do trabalho em saúde: excessos e invisibilidade no trabalho da enfermagem em oncologia. Saúde debate [Internet]. 2015 [acesso em: 04 dez. 2018];39(spe):298-306. Disponível em: https://doi.org/10.5935/0103$\underline{1104.2015 S 005247 .}$.

16. Abdellah RF, Salama KM. Prevalence and risk factors of workplace violence against health care workers in emergency department in Ismailia, Egypt. Pan Afr Med J [Internet]. 2017 [acesso em: 04 dez. 2018];26:21. Disponível em:

https://doi.org/10.11604/pamj.2017.26.21.10837.

17. Eslamian J, Akbarpoor AA, Hoseini SA. Quality of work life and its association with workplace violence of the nurses in emergency departments. Iran J Nurs Midwifery Res [Internet]. 2015 [acesso em: 04 dez. 2018];20(1):56-62. Disponível em: https://www.ncbi.nlm.nih.gov/pmc/articles/PMC4325414/.

18. Silva AA, Menegat RP. A gestão do cuidado em relação à autonomia dos enfermeiros. Revista Eletrônica Gestão \& Saúde [Internet]. 2014 [acesso em: 04 dez. 2018];5(4):2294-312. Disponível em:

http://periodicos.unb.br/index.php/rgs/article/view/13792. 